\title{
CADEIRA DE LITERATURA BRASILEIRA
}

\section{HISTORICO}

Com a fundação da Faculdade de Fulosofla, Clenclas e Letras da Universidade de Săo Paulo (Dec. 6239, de 25/1/1934) fol crlada a Cadeira de Literatura LusoBraslleira, cujo regente fol o Prof. Fidelino de Figueiredo. Em 1989, fol desdobrada em Cadeira de Literatura Brasllelra e Cadeira de Literatura Portuguesa. Para reger a primelra, interinamente, o Prof. Dr. Mário Pereira de Souza Lima fol nomeado por decreto de 11 de julho de 1939, tendo passado a Catedrático por Concurso de provas e titulos em 1945 (decreto de 14 de agosto de 1945). Permaneceu nestas funç̋es até 1963, quando fol substituido pelo Pror. Dr. José Aderaldo Castello.

De Janeiro a dezembro de 1944, o licenclado Manuel Cerqueira Leite exerceu as funçes de 10 assistente; de outubro de $1945 \mathrm{em}$ diante, estas funçőes passaram a ser exercidas pelo licenciado José Aderaldo Castello, posteriormente assistente-doutor e finaimente assistente-docente, em virtude dos concursos de doutoramente e de livre-docencla a que se submeteu, respectivamente, em 1950 e em 1958.

Quando o Prof. Dr. Márlo Perelra de Souza Lima estêve nos Estados Unidos, de agósto de 1947 a janeiro de 1949, fol Indlcado para substitul-lo, como de direlto, um livre-docente, tendo recaldo a escolha no professor Dr Manuel Cerquelra Lelte.

Em 31 de agosto de 1963, com a aposentadorla do Prof. Mario Pereira de Souza Lima, o Prof. Dr. José Aderaldo Castello passou a reger a Cadelra a titulo precário; em 1965, submetido a Concurso de provas e titulos, passou a Professor Catedrático. Para substituí-lo nas suas funç̄es anteriores de assistente, fol Indicado o Prof. Dr. Rolando Morel PInto. O Licenciado Fernando Carvalho, que se achava entăo como instrutor, por sua vez pediu rescisăo de contrato $(15 / 10 / 63)$ em virtude de haver sido indicado para professor da Cadeira de Literatura Brasileira da Faculdade de Fllosofia, Ciencias e Letras de Rio Preto. Posteriormente, foram nomeados outros dois instrutores: as licenciadas Neusa Pinsard Caccese e. Aliette Fontana, e um professor-colaborador, especializado em assuntos de teatro, 0 Prof. Declo de Almeida Prado.

En maio de 1967, o Dr. Rolando Morel Pinto, assistente-docente, pediu sua demissåo. Para substitui-1o, fol indicado o Prof. Dr. José Carlos Garbuglio. 


\section{CORPO DOCENTE ATUAL}

Professor emérito: Dr. Márlo Pereira de Souza Lima (aposentado).

Professor Catedrático: Dr. José Aderaldo Castello.

Professor-colaborador: LIc. Déclo de Almeida Prado.

Assistente-doutor: Dr. Jose Carlos Garbuglfo.

Instrutores: Licencladas Neusa Pinsard Caccese e Allette Fontana.

\section{DOUTORAMENTOS}

1. Em 1950 - José Aderaldo Castello - A Introduçao do Romantismo no Brasil.

2. Em 1961 - Rolando Morel PInto - Graciliano Ramos - Ator $\theta$ autor.

3. Em 1965 - José Carlos Garbuglio - $O$ universo estético de Graca Aranha.

4. Em 1967 - Luiz Geraldo de Toledo Machado - Antonio de Alcantara Machado o o Modernismo.

\section{LIVRE-DOCENCIA}

1. Em 1958 - Dr. José Aderaldo Castello - José Lins do Régo e o movimento regionalista $e$ tradicionalista.

2. Em $1966 \rightarrow$ Dr. Rolando Morel Pinto -4 oxperiéncia $e$ a ficçāo de Oliveira Paiva.

\section{CONCURSO DE CATEDRA}

1. Em 1945 - Dr. Márlo Pereire de Souza Lima - Os Fenómenos Estéticos na Poesia Brasileira do Parnasianismo ao Modernismo.

2. Em 1965 - Dr. José Aderaldo Castello - Realidade o Iltısāo em Machado de Assis.

\section{DOUTORAMENTOS EM ANDAMENTO:}

Orlentador - Prof. Dr. José Aderaldo Castello.

Licenclados:

1. José Eduardo de Oliveira - Ingles de Souza.

2. Gllberto Mendonca Teles - Hugo de Carvalho Ramos.

\section{INSTITUTOS UNIVERSITARIOS}

A Cadelra de Llteratura Brasileira faz parte integrante do Instituto de Estudos Braslleiros da Universldade de Săo Paulo, conforme portaria G.R. no 5, de 9/1/1963, do Magnifico Reltor da U.S.P.

\section{BIBLIOTECA}

Nưmero aproxlmado de volumes: 4.000, inclusive algumas coleç̄es de revistas Importantes como a "Revista da Academia Brasileira de Letras", a "Revista Braslleira", 3* fase, e a "Revista do Brasil".

\section{ASSOCIAÇAO OU SOCIEDADES DIRETA OU INDIRETAMENTE LIGADAS A CADEIRA}

A Cadeira de Literatura Brasileira prende-se à Comissão de Literatura do Conselho Estadual de Cultura da Secretaria do Governo de S. Paulo, com representaç̃o permanente; faz parte dos Conselhos do Instituto de Cultura Hispanica e do Instituto de Estudos Arabes de S. Paulo. 


\section{PUBLICAÇOES}

De José Aderaldo Castello:

1. Pela F.F.C.I. - Secçăo de Publlcaçóes:

- A polamica sobre "A Confederaçáo dos Tamoios", textos crítcos, com introducāo por José Aderaldo Castello, 1953.

2. Pela Comissăo de Literatura - Conselho Estadual de Cultura, organizados e prefaclados por José Aderaldo Castello:

- Homens e Intençōes, 1959.

- Antologia do Ensaio Literário Paulista, 1961.

- Textos que interessam a História do Romantismo no Brasil - vol. I, 1961; vol. II, 1963; vol. III, 1964.

- Maclel Montelro - Poesias, 1963.

- Método e Interpretacão, 1965.

3. Obras especializadas e didáticas:

- José Lins do Régo - Modernismo e Regionalismo, 1961.

- Aspectos do Romance Brasileiro, 1961.

- Machado de Assis - Crftica, 2* ed., 1961.

- Goncalves de Magalhães - Trechos escolhidos, 1961.

- A Literatura Brasileira - vol. I - Manifestacōes Literórias da Era Colonial (1500/1808/1836), 2s ed., 1966.

- Presenca da Literatura Brasileira - História e Antologia, 3 vols., em colaboraçăo com Antónto Cândłdo de Mello e Souza, 2" ed., 1966.

De Rolando Morel PInto:

Graciliano Ramos - Ator 6 Autor, 1962

Estudos de romance, 1965

De Déclo de Almeida Prado:

Apresentaçāo do Teatro Brasileiro Moderno, 1956.

Teatro em Progresso, 1964

4. Periódicos em que os docentes-geralmente publicam seus trabalhos:

"Revista do Instituto de Estudos Braslleiros"; "Revista de Letras" da Faculdade de Letras de Assis - S. Paulo; "Alfa", Revista da Faculdade Filosofia e Letras de Marilia - S. Paulo; "Suplemento Literário" de "O Estado de S. Paulo" - S. Paulo; eventualmente, em outros periódicos nacionals e estrangeiros.

\section{INSTALAÇOES}

A Cadeira dispōe de três salas onde se acham instalados o gabinete de trabalho do pessoal docente e a biblioteca, esta privativa dos alunos do Departamento de Letras, sito a Rua Maria Antonia, 258.

Instalaçes futuras - Cldade Universitária, Edificlo de Letras.

\section{CURSO DE GRADUAÇAO - BACHARELADO}

- A Cadeira de Literatura Brasileira e ministrada para os Cursos de Letras Neolatinas, Anglo-germanicas, Clássicas e Vernáculas -, portanto a todos os alunos do Departamento de Letras. 
O número de aulas ministradas rëgularmente soma um total de 28 aulas semanala. Conslderem-se, alnda mais, os seminários, de acordo com o quadro abaixo:

I A1llas mifnstradas no Perfodo Diurno:

20 ano $-\quad 3$ aulas;
30 ano $-\quad 3$ aulas;
40 ano $-\quad 3$ aulas;

Pós-graduaçāo - 19 e $2 \circ$ anos -4 aulas; seminários de grupos, para orlentacăo de trabalhos de aproveltamento; horárlos para orlentaçăo de grupo de bolsistas estrangeiros. As horas-seminários săo variávels.

II Aulas ministradas no Perfodo Noturno:

$$
\begin{aligned}
& 20 \text { ano } \quad-\quad 3 \text { aulas; } \\
& \text { 30 ano }-3 \text { aulas; } \\
& 40 \text { ano }-\quad 3 \text { aulas; }
\end{aligned}
$$

Além dos trabelhos dídáticos, de acórdo com o esquema acima indicado, a Cadeira desenvolve os segulntes planos de trabalhos:

I Pesquisa sistemática no campo da História Literária do Brasll, utillzando éditos e Inéditos, para flxaç̄o e estabeleclmento de textos e para a dlvulgaçăo de documentaçăo indispensável aos estudos da especialldade, conforme várlas publicaçóes já exlstentes.

IT Plano de organizaçăo de um arquivo de Intormaçao blo-bibllográflca, que deverá ser contlnuamente revista e atuallzada.

IIr Particlpacáo nos programas de trabalhos - ensino e pesquisa $\rightarrow$ de outras institulços, notadamente o Instltuto de Estudos Brasilelros e a Comissåa de Literatura do Conselho Estadual de Cultura de Săo Paulo.

\section{PROGRAMAS}

Desde a criaçăo da Cadelra de Literatura Brasllelra, os fundamentos da orlentacăo didática adotada tem sido quase sempre os mesmos. Além da introduç̃o metodológica que de ordinário acompanha os cursos, acentuam-se o estudar e a discussäo de problemas básicos e gerals da histórla literária do Brasil, bem como - desenvolvimento de cursos monográflcos sóbre os princlpais autores ou movimentos literárlos. Dlspensa-se especlal culdado a blbliografia geral indicada e comentada, a relaçáo de obras cuja leltura é recomendada ou dada em caráter obrigatório, e à exigencla dos "trabalhos de aproveltamento".

Asalm, os programas de Literatura Brasilelra, para os cursos de Letras, sũo organizados com o obfetlvo de proporcionar aos alunos, ao longo dos tres anos de estudos regulares, uma visăo ampla da evolucăo da nossa literatura, desde os seus primórdios até ao Modernismo. sste movlmento, por sua vez, é objeto de cursos especlais ou de pós-graduacto.

De modo geral, a distribuiçáo da matéria, lecionada e discutida, leva em conslderacăo as possibllidades de aproveltamento e experiencla dos alunos, Os cursos iniclais tem, princlpalmente, caráter panoramico e informativo e visam a integrar o principlante na realldade especifica que é a "literatura brasllelra". A partir do segundo ano curricular, reduz-se o ambito da matéria em beneficio do sua profundldade. Săo estudados os princlpais movimentos literálos do século XIX, dando-se enfase a um autor dos mais representativos de cada estilo, atraves 
da análise de suas obras principais. Dêsse modo, o aluno flca iniciado náo 80 nos problemas da nossa Histórja Literála, mas também ensala os prímelros passos na Critica.

Especificando, transcreve-se a seguir o atual programa, previsto para 1967:

\section{PROGRAMA DA CADEIRA DE LITERATURA BRASILEIRA}

\section{Segundo ano}

Introduçăo ao estudo da Literatura Brasilelra: bibliografla essencial; a evoluçá do pensamento critico; conceito, caracteristicas gerafs e o problema dos espacos históricos na Literatura Braslleira. O Século XVI: Anchleta. O Barroco: Gregorio de Matos. O Arcadismo: Cláudio Manuel da Costa. O Romantismo: definlçăo e quadro geral. O Romance Romântlco: José de Alencar. A poesla romantica: Goncalves Dlas.

\section{Terceiro ano}

O Realismo: definiçāo e quadro geral. Aluisio Azevedo. O Parnasianismo: defintç̄o e quadro geral. Olavo Bllac. O Simbolismo: definiçăo e quadro geral. Cruz e Souza. Raul Pompéla. Panorama do teatro no século XIX: Martíns Pena e Artur Azevedo.

Quarto ano

Machado de Assis. A poesla modernista: Manuel Bandeira. O romance modernista: Graciliano Ramos.

Pós-graduaçio (dois anos)

I Revisão geral da Literatura Brasileira:

a. História e pensamento crítico;

b. Prosa - 1. Crônica histórica (sécs. XVI, XVII, XVIII);

c. Poesia;

d. Teatro (poesia e prosa).

II Blbllografla - Trabalhos de levantamento, pesquisa e reconhecimento de ediçơes básicas.

III Investigaça e pesquisas em biblfotecas, arquivos, etc.

IV Cursos monográficos e seminários sóbre periodos e autores.

V Elaboraçăo de uma monogratia sobre assunto de llvre escolha.

\section{PESQUISAS REALIZADAS E EM ANDAMENTO}

1. Com o patrocinlo da Comissāo de Literatura do Conselho Estadual de Cultura vem sendo feito um levantamento de esparsos em revistas e jornais do seculo XIX, trabalhos criticos e históricos que interessam ao estudo do Romantismo no Brasil. J6 foram publicados tres volumes sob o titulo geral Textos que interessam d História do Romantismo no Brasil, organizados e prefaclados por Jose Aderaldo Castello, enquanto se aguarda a publicaçăo de outros volumes em fase de pesquisa e organizaçăo.

2. Pesquisa sobbre o "Movimento Academicista" no Brastl, de 1724 a 1820 , abrangendo as academfas hlstóricas, literárlas e clentificas, os "atos academicos" e os "Iestejos públicos comemorativos" exlstentes e organizados em diferentes partes do Brasil: Pará, Maranháo, Pernambuco, Bahla, Minas Gerals, Culabá, Rlo de Janeiro e S5̆o Paulo. Já fol feito o levantamento de cerca de quarenta obras impressas e inéditas, entre coletaneas - prosa, poesła e teatro, - e "relacóes" descritivas. Seu Interesse é maltiplo: geografico, etnografico, histórico, sociologico, literálo, Inguistico, sendo fundamental para a caracterizacto do Barroco no Brasil. A pesquisa, planejada e realizada pelo Catedrático de Literatura Brasileira, 
Prof. Dr. José Aderaldo Castello, teve o apolo da Fundaç̄o de Amparo a Pesquisa do Estado de Săo Paulo, do Instituto Histórico e Geográfico Brasllelro, do Rlo de Janelro, e agora continua em colaboraço com o Instituto de Estudos Brasileiros da Unlversidade de Săo Paulo, do qual a Cadeira de Literatura Brasllelra é integrante. Contou com o precloso auxilo do Professor Dr. Isaac Nicolau Salum, no concernente à flxacăo dos textos em latim, e tem como auxiliar permanente a Licenclada Yedda Dlas Lima, além. de outros colaboradores eventuais. Deu-se Inicio à sua publicaçăo que atingirá de 10 a 12 volumes, aproximadamente com 350 páginas cada um.

3. Planos em estudo para pesquisas sóbre o romance brasileiro a serem executados pelas licenciadas Neusa Pinsard Caccese e Allette Fontana, ambas Instrutoras da Cadelra de Literatura Brastleira.

4. Plano para participar da pesquisa conjunta, que se acha em estudo, do Instituto de Estudos Braslleiros da Universidade de Sāo Paulo, sôbre múltíplos aspectos do Brasil de 1808 a 1822 .

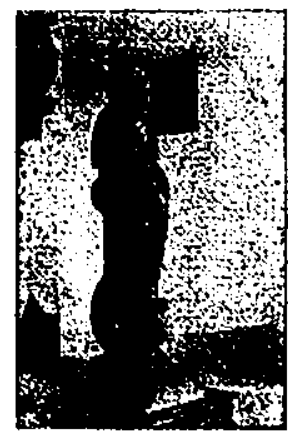

